\title{
Mechanochemical Treatment of Petroleum Residues and their Mixtures with Brown Coal
}

\author{
A.K. Golovko'*, B. Davaatseren ', K.S. Dneprovsky', V.G. Surkov' and O.I. Lomovsky² \\ 1 Institute of Petroleum Chemistry, Siberian Branch of the Russian Academy of Sciences, 3, Academichesky Av., 634021, Tomsk - Russia \\ 2 Institute of the Solid State Chemistry and Mechanochemistry, Siberian Branch of the Russian Academy of Sciences, \\ 18, Kutateladze Str., 630128, Novosibirsk - Russia \\ e-mail: golovko@ipc.tsc.ru - davaatomsk@yahoo.com -dnepr@ipc.tsc.ru - sur@ipc.tsc.ru - lomov@solid.nsc.ru \\ * Corresponding author
}

Résumé - Traitement mécanochimique du pétrole lourd et des mélanges des résidus pétroliers avec le charbon - On a examiné l'influence d'un traitement mécanique sur la composition, les propriétés et la transformation des composants de mazouts (résidus de distillation $>350^{\circ} \mathrm{C}$ ) et d'huile dégazolinée jusqu'à $200^{\circ} \mathrm{C}$. On a établi que l'influence de l'énergie mécanique sur l'huile dégazolinée en présence du quartz naturel mène à la division par près de deux de la concentration en $n$-alkanes et à la formation de fractions légères, d'hydrogène et de gaz hydrocarbonés. Il est possible d'obtenir des fractions essence et diesel par la dégradation mécanochimique de l'huile dégazolinée. Le rendement augmente en présence de particules de quartz. Le degré de dégradation des composants du mazout augmente si le mazout a été préalablement ozoné, puis mélangé avec $5 \%$ de tétraline (donneur de l'hydrogène) avant d'être soumis au traitement mécanique. Il est montré que les transformations des composants du mazout et du charbon interviennent lors du traitement mécanique.

\footnotetext{
Abstract - Mechanochemical Treatment of Petroleum Residues and their Mixtures with Brown Coal - The influence of mechanical treatment $(M T)$ on the composition, properties and transformations of crude oil devoid of gasoline fractions boiling up to $200^{\circ} \mathrm{C}$ and petroleum residua $>350^{\circ} \mathrm{C}$ (mazouts) was studied. It was established that the impact of mechanical energy upon crude oil in the presence of quartz. particles almost halves the concentration of n-alkanes in the raw material and leads to formation of lowboiling fractions, hydrogen and hydrocarbon gases. The possibility of producing gasoline and diesel distillates from degasolined oil by means of its mechanochemical treatment is shown. The yields of these distillates increase when the stock is treated in the presence of quartz particles. The degree of destruction of mazouts rises if the raw material was ozonizated, then mixed with 5\% of tetraline (H-donor), and finally subjected to mechanical treatment. It was shown that transformations of both coal and mazout components occur during mechanical treatment of mazout/coal mixtures.
} 


\section{INTRODUCTION}

The production of heavy high-viscous crude oils has increased permanently in recent years. Such oils contain large amounts of solid paraffin, resins and asphaltenes and are extremely poor in light fractions, and so the necessity exists to develop effective, ecologically neat technologies to process such kinds of stocks. The mechanoactivation influence upon oil components should permit the heightening of the efficiency of petroleum refining and the simplification of the apparatus get-up of the processes [1].

Mechanochemical reactions differ essentially from classic thermal and thermocatalitic reactions by an absence of olefins and hydrogen, being obligatory cracking products of hydrocarbons (HCs). Similar phenomena were observed earlier as heavy fragments of polymer chains were not found after mechanical destruction of the polymers [2].

Former investigations of MT of heavy petroleum components in mills of the planetary type showed the potential possibility of initiating radical reactions in the liquid phase [3].

The type of activator, and material nature of the activator and grinding bodies, as well as the presence of especially introduced solid particles play a significant role in the mechanical activation (MA) of the processes [4]. Thus, when mechanically treating and grinding crystalline quartz, a large amount of different structural defects are formed. The most active of them are radical centers serving as initiators of chemical transformations of gaseous [5] and liquid [6] HCs.

Both hydrogen and tetraline-like proton-donor HCs may be used as hydrogenating agents. It is known that the reactions of rupturing of reaction chains, the stabilization of radicals and formation of stable final mechanochemical products are very manifold [7]. The radicals can recombine when mechanically treating the substances in the absence of foreign matters.

The most common reason for chain ruptures is an interaction of radicals with different acceptors. Chain ruptures may also occur owing to formation of metal-organic compounds on the walls of the employed equipment.

The vast resources of little-used carbonaceous raw materials are represented by low-energy and off-grade brown coals. Their involvement in processing as supplementary raw materials for liquid fuel production is attractive for the fuel and chemical industries. The degree of organic mass conversion by coal fluidization and distillate yield is enhanced by mechanoactivation of solid fuels and high-boiling petroleum residues, joint and several [8].

The results of our experiments on MT of petroleum residua and their mixtures with brown coal are presented here. The processing of such mixtures will permit the widening of the stock basis for motor fuel production [9] and the involvement of working up solid combustible fossils.

\section{EXPERIMENTAL}

The studied objects were degasolined oil from Tamsagbulag field (Mongolia) and residua $>350^{\circ} \mathrm{C}$ (mazouts) obtained by distillation of the same oil and of crude oil from Talakanskoe field (Yakutia-Sakha Republic, Russia) as well as brown coal from Kangalas field (Lena basin, Yakutia-Sakha Republic). The coal was a typically humus, vitrinitic one, bright upon fracture, with an ash content of $11.8 \mathrm{wt} . \%$ and humidity of 12.7 wt.\%. The elemental composition of the brown coal is $\mathrm{C}-71.5 ; \mathrm{H}-5.5 ; \mathrm{S}-0.4 ; \mathrm{N}-0.8 ; \mathrm{O}-21.8$ wt.\% on daf $(\mathrm{Vdaf}=46.6 \%)$. The coal fraction used contained particles of $0.036-0.200 \mathrm{~mm}$ in size.

MA experiments were performed using an AGO-2 unit equipped with an activator of the planetary, friction type [10]. Still balls $8 \mathrm{~mm}$ in diameter (the weight of one ball is $1.8 \mathrm{~g}$ and number of balls is 60) served as grinding bodies. The centrifugal acceleration of the lasts was equal to $600 \mathrm{~m} / \mathrm{s}^{2}$.

The reactor had a still hollow cylinder $150 \mathrm{~cm}^{3}$ in volume. The reactor was filled with still balls to one-third of its volume; another one-third contained the product being studied, the rest being airspace. This corresponds to the percussivescuffing mode of unit operation, providing the maximal influence of the milling bodies upon the object studied.

Quartz (particle sizes of $0.2 \mathrm{~mm}$ ) was used as mineral addition.

To mechanically treat the degasolined Tamsagbulag oil sample, it was fed into the reactor already containing the grinding bodies and quartz particles, and MT was performed for 10 minutes. The experiments on MT of mazout from Tamsagbulag oil with or without quartz additions were continued for $30 \mathrm{~min}$.

The samples of mixtures of brown coal with mazout from Talakan oil were made up at coal/mazout proportions of $10: 90 ; 20: 80 ; 30: 70 ; 40: 60$ by weight, tetraline serving as proton-donor in all cases.

The physicochemical characteristics of the initial stocks and products obtained were determined by standard methods $[11,12]$. Group compositions of the substances were also established using well-known procedures [13] consisting of asphaltene precipitation by forty-fold excess of $n$-hexane and adsorption separation of oily and resin fractions in a Soxhlet apparatus (adsorbent - silica gel of ASK grade, the solvents when eluting oils and resins were $n$-hexane and 1:1 benzene + ethanol mixture, respectively).

The analysis of individual saturated HCs was done using a "Crystall-2000M" gas chromatograph (flame-ionization detector, quartz capillary column 25 meters long, $0.22 \mathrm{~mm}$ in internal diameter, stationary phase - polydimethylsiloxane SE-52, linear increase in temperature from 50 up to $290^{\circ} \mathrm{C}$ with a rate of $3 \mathrm{grad} / \mathrm{min}$ ). The concentrations of individual HCs were calculated by the method of internal standard, the last being $n$-hexadecane. 
The products of MT of coal-mazout mixtures were separated in a Soxhlet apparatus, consequently extracting liquid substances with benzene and chlorophorm. Residuary solid material was further dissolved in tetraline in a laboratory micro-autoclave [14] (30 $\mathrm{cm}^{3}$ volume) equipped with a low-speed stirrer. Thermal liquefaction of solid coal substances was performed in helium medium, at a solid/tetraline proportion of $1: 2$, and the temperature was increased from 250 up to $450^{\circ} \mathrm{C}$ with a constant heating rate of $2.5 \mathrm{grad} / \mathrm{min}$. Upon reaching the adjusted temperature the liquefaction process was interrupted sharply by cooling the autoclave with cold water. Conversion of coal into benzene-soluble products and yields of gas and asphaltenes were determined in each experiment. The petroleum studied was separated into fractions of saturated, mono-, bi- and tricycloaromatic HCs by liquid-adsorption chromatography in columns $100 \mathrm{~cm}$ long and $1.5 \mathrm{~cm}$ in internal diameter using aluminum oxide with activity grade II on the Brokman scale as adsorbent (adsorbent)/(product separated), the proportion being equal to $80: 1$ by weight, and $n$-hexane and, further, its 3:1 mixture with benzene serving as chromatographic eluents. The eluates, each $5 \mathrm{~cm}^{3}$ by volume, were gathered into test tubes with a rate of $0.5 \mathrm{~cm}^{3} / \mathrm{min}$ and further analyzed by means of thin-layer chromatography on Silufol plates, a $n$-hexan+chlorophorm mixture serving as developing system in the chamber with ascending flow. $R_{f}$ values measured of separate groups of HCs were compared with those determined for authentic $n$-hexylbenzene, 1,6-dimethylnaphthaline, phenanthrene and chrysene during parallel separation of their standard mixture (20:5:3:1 by volume) under the same chromatographic conditions. On the basis of their $R_{f}$ values the eluates gathered were sorted into common saturated, mono- biand triarenic hydrocarbon fractions, finally analyzed after distilling the solvent off by means of gas-liquid chromatography.

\section{RESULTS AND THEIR DISCUSSION}

\subsection{Mechanical Treatment of Oil Stock in the Presence of a Solid Phase}

The physicochemical characteristics of degasolined Tamsagbulag oil before and after its mechanical treatment in the presence of quartz particles are given in Table 1.

It can be seen that degasolined oil, both initial and mechanically treated, does not flow at room temperature; at 30 and $40^{\circ} \mathrm{C}$ the treated oil has a viscosity 3.2 times and 2.1 times, respectively, lower than the initial sample.

The concentration of asphaltenes in the petroleum is increased after its mechanical treatment, while resin amounts remain almost the same. The treatment also affects the contents of $n$-alkanes in the oil (Fig. 1). The portion of $n$-alkanes in the treated oil, solid paraffin $\mathrm{C}_{17}+$ included, is much less than in the initial sample: the appearance of their molecularmass distributions remains almost as before.
TABLE 1

Physicochemical properties of initial and mechanically-treated petroleum residues $>200^{\circ} \mathrm{C}$

\begin{tabular}{l|c|c}
\hline \multirow{2}{*}{ Indices } & \multicolumn{2}{|c}{ Values } \\
\cline { 2 - 3 } & before MT & after MT \\
\hline Kinematic viscosity, cSt: & not flowing & not flowing \\
at $20^{\circ} \mathrm{C}$, & 42.64 & 13.40 \\
at $30^{\circ} \mathrm{C}$ & 19.49 & 9.14 \\
at $40^{\circ} \mathrm{C}$ & & \\
\hline Content, wt.\% of: & 0.29 & 0.48 \\
asphaltenes & 3.31 & 3.47 \\
resins & 96.40 & 96.05 \\
hydrocarbons & 35.28 & 19.48 \\
total $n$-alkanes & 24.04 & 13.53 \\
solid paraffin $\left(n\right.$-alkanes $\left.\mathrm{C}_{17}+\right)$ & 200.0 & 64.0 \\
\hline Initial boiling point, ${ }^{\circ} \mathrm{C}$ & & \\
\hline Content, wt.\%, of fraction: & - & 9.10 \\
IBP-200 ${ }^{\circ} \mathrm{C}$ & 34.50 & 48.30 \\
IBP-350 ${ }^{\circ} \mathrm{C}$ & &
\end{tabular}

Fractional distillation of both oil samples showed that the products of mechanical treatment have an initial boiling point much lower than degasolined raw material. $9.1 \mathrm{wt} . \%$ of HCs boiling at temperatures lower than $200^{\circ} \mathrm{C}$ appear in the treated oil composition. Its $\mathrm{IBP}-350^{\circ} \mathrm{C}$ fraction content rises by $13.8 \mathrm{wt} . \%$. The gases, namely, hydrogen (65.4 vol.\%), methane (33.8 vol.\%) and traces $(0.8$ vol. $\%)$ of ethane, were also formed in the course of mechanical destruction.

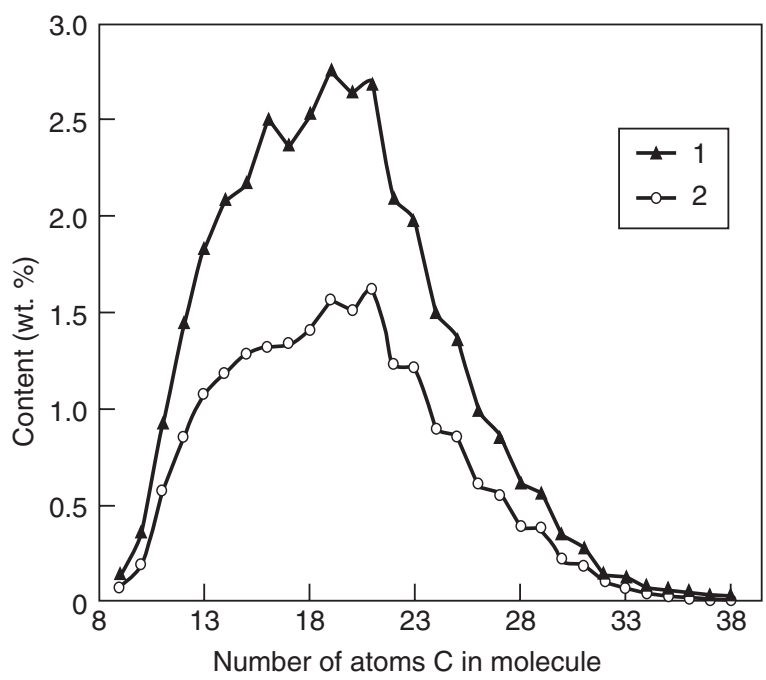

Figure 1

Molecular-mass distributions of $n$-alkanes in initial (1) and mechanically-treated (2) Tamsagbulag oil. 
We believe that the destruction mechanism of HCs during MT is complex. The origin of this radical process occurs, probably, at the time of demolition of the quartz crystals. Chemosorption centers may become ruptured or strained Si-O bonds. Molecules of heavy petroleum components may be adsorbed on such centers followed by splitting of the weakest bonds and formation of low-molecular radicals originating from the chain process as a whole.

\subsection{Mechanical Treatment of Mazout in the Presence of a Hydrogen Donor}

Experimental data on the influence of tetraline upon yield of light fractions during MT of mazout are given in Figure 2.

As it can be seen from the data obtained, the yield of light fractions from mazout is increased from 5.7 to $9.1 \mathrm{wt} . \%$ when tetraline addition is increased up to $5 \%$. A rise in the tetraline amount above $5 \%$ has no influence on the yield of light fractions $(\simeq 5 \mathrm{wt} . \%)$. It can be supposed that addition of $5 \%$ of tetraline is sufficient to hydrogenate all formed hydrocarbon radicals.

It was shown earlier [15] that amounts of resins and asphaltenes in Tamsagbulag petroleum residues are increased essentially after their ozonization. In this work, MT (30 minutes) of ozonizated residues followed by thermolysis of ozonization products at $350^{\circ} \mathrm{C}$ for 1 hour was performed to destroy high-molecular compounds formed in this way.

To heighten yields of light fractions $5 \mathrm{wt} . \%$ of tetraline were also added to the residues ozonizated. The results obtained are presented in Table 2.

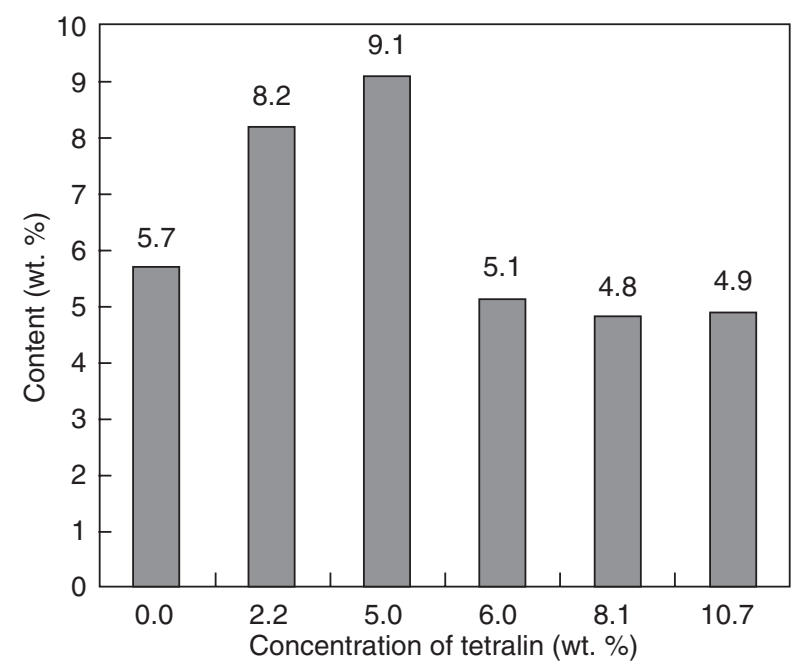

Figure 2

Yield of IBP- $350^{\circ} \mathrm{C}$ during mechanical treatment of mazout in the presence of different amounts of tetraline.
TABLE 2

The yields of IBP- $350^{\circ} \mathrm{C}$ distillates from Tamsagbulag mazout under different conditions of its processing

\begin{tabular}{c|c|c}
\hline $\begin{array}{c}\text { Test } \\
\text { number }\end{array}$ & Scheme of processing & $\begin{array}{c}\text { Yield, } \\
\text { wt.\% }\end{array}$ \\
\hline 1 & Ozonation $\rightarrow$ MT $\rightarrow$ Thermolysis & 6.3 \\
\hline 2 & Ozonation $\rightarrow$ MT with 5 wt.\% of tetraline & 3.6 \\
\hline 3 & $\begin{array}{r}\text { MT with 5 wt.\% of tetraline } \rightarrow \\
\text { Ozonation } \rightarrow \text { Thermolysis }\end{array}$ & 3.8 \\
\hline 4 & $\begin{array}{c}\text { Ozonation } \rightarrow \text { MT with 5 wt.\% } \\
\text { of tetraline } \rightarrow \text { Thermolysis }\end{array}$ & 4.7 \\
\hline 5 & $\begin{array}{c}\text { Ozonation with 5 wt.\% } \\
\text { of tetraline } \rightarrow \text { MT } \rightarrow \text { Thermolysis } 6.3\end{array}$ & 19.5 \\
\hline
\end{tabular}

For experiments performed in the absence of tetraline, $6.3 \mathrm{wt} . \%$ of the IBP $-350^{\circ} \mathrm{C}$ fraction were formed after MT of mazout for $30 \mathrm{~min}$. In the other cases, besides experiment 5 , the yield of this fraction was somewhat less.

The best result was obtained when tetraline was introduced into the mazout composition before its ozonolysis and mechanical treatment; an additional $19.5 \mathrm{wt} . \%$ of motor fuels were produced instead of only $6.3 \mathrm{wt} . \%$ when processing mazout without tetraline addition.

These data demonstrate that mainly high-molecular compounds are converted into lower ones during mechanical treatment of ozonizated mazout.

\subsection{Mechanochemical Treatment of Mazout/Coal Mixtures}

The influence of mechanical treatment upon the composition and properties of mazout/coal mixtures was estimated by the coal conversion degree $(\alpha)$, calculated by accounting for the ash content of the initial coal $\left(A_{\mathrm{o}}\right)$ and of that treated in the presence of the liquid phase $(A)$ as:

$$
\alpha=100\left(1-A_{\mathrm{o}} / A\right) /\left(100-A_{\mathrm{o}}\right) \text {. }
$$

The data on coal conversion during MT in tetraline or mazout media are presented in Table 3.

As it can be seen, the results of treatment in tetraline or mazout media are somewhat different, but the common character of the MT influence is approximately similar.

These experimental data are indirectly indicative of the occurrence of mechanochemical reactions due to quasiautoclave conditions (increased temperature and pressure) appearing in the course of mechanical treatment of liquid/solid binary systems.

Thus, the maximal effect was reached in the cases of low concentration of coal in the mixture (10-20 wt.\%). An influence of quasi-autoclave conditions seems to be realized on the level of each separate coal particle impregnated with the solvent and containing gas inclusions in its porous structure. 
TABLE 3

Coal conversion degrees during mechanical treatment depending on coal:solvent proportions

\begin{tabular}{c|c|c}
\hline \multirow{2}{*}{$\begin{array}{c}\text { Coal content of mixture, } \\
\text { wt.\% }\end{array}$} & \multicolumn{2}{|c}{ Coal conversion degree, \% } \\
\cline { 2 - 3 } & in tetraline & in mazout \\
\hline 10 & 26.6 & 19.5 \\
20 & 19.4 & 20.1 \\
30 & 11.5 & 12.4 \\
40 & 11.5 & 16.2 \\
50 & 12.4 & - \\
60 & 13.2 & - \\
70 & 2.0 & - \\
\hline
\end{tabular}

When the coal content of the mixture increases above 50 wt.\% the effect of MT practically disappears because of the insufficient kinetic energies of the milling bodies moving in viscous paste.

For comparative estimation of a quasi-autoclave regime under conditions of high-strained mechanical treatment in solvent media, traditional liquefaction of the same brown coal in tetraline medium was done at temperature intervals of 250-450 $0^{\circ}$ (Fig. 3).

Curves (1-3) reflect the temperature dependences of total coal conversion and yields of asphaltenes and gaseous products. They may be used to control the influence of mechanical treatment on the coal liquefaction process.

Comparison of the results presented in Figure 3 with the data on group compositions of mazout and its mechanical processing products presented in Table 4 show that coal conversion degrees reached when treating coal mechanically in tetraline and mazout correspond approximately to those observed at temperature intervals of 300-370 and $340-360^{\circ} \mathrm{C}$, respectively, in traditional coal liquefaction in the autoclave.

The dependence of conversion degree coal organic components (COC) during thermal solution solid residues after MT of coal in tetraline at a coal/solvent proportion equal to 50:50 is also shown in Figure 3 (curve 4). Temperature dependences of conversion degrees of these residues and of COC from the initial coal have forms which are identical and characteristic of the non-isothermal liquefaction method.

The maximum of the solution rate of the residues is somewhat shifted into the higher temperature region, but the final conversion degree is larger than for the initial coal (66.3 instead of 56.8 wt.\%).

The decrease in the COC conversion degree of mechanically-treated residues in the low-temperature region may be explained by preliminary extraction elimination of soluble coal components, both occurring in the initial sample (coal bitumoids) and formed anew by MT. The total content of such components in this coal sample was $12.4 \mathrm{wt} . \%$.

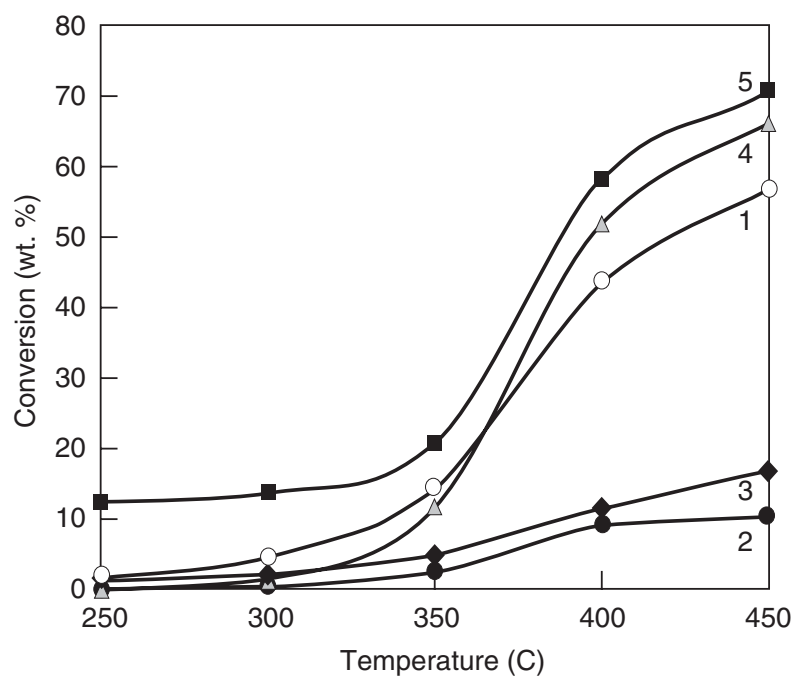

Figure 3

Results of thermal dissolving of brown coal in tetraline (50:50)

1 - Conversion of initial brown coal;

2 - Yield of asphaltenes;

3 - Yield of gaseous products;

4 - Conversion of the residues remaining after MT

5 - Total conversion degree of mechanically-treated sample.

The macromolecular part of COC remained after MT and exhaustive extraction, containing more thermally durable bonds: therefore, their thermal destruction begins at higher temperatures. However, mechanochemical transformations occurring in the medium of the hydrogen-donor solvent possibly favor formation of new molecular and over-molecular structures preventing polycondensation reactions during thermal solution. As a result, the final conversion degree of coal is increased compared with the initial one [16].

The sum curve for the dependence of the conversion degree accounting for yield of extractable products of coal transformations (curve 5) demonstrates the very great efficiency of the preliminary mechanical activation process (the total conversion degree is equal to $70.5 \%$ instead of $56.8 \%$ for the initial coal).

As shown in Table 4, the initial mazout contains 2.5 wt.\% of asphaltenes, their amounts diminishing down to $2.0 \%$. MT products of all mazout/coal mixtures contain amounts of asphaltenes 1.5-2.0 times less than the initial mazout.

Mazout and the products by MT of coal/mazout mixtures contain higher amounts of saturated HCs compared with aromatic ones.

Initial mazout contained 46.9 wt.\% of saturated HCs. Their content increases after MT of mazout or its mixtures with the coal, becoming comparable with that observed in the mazout only at coal/mazout proportions of 40:60 and 50:50. Further increase in the coal portion in mixtures leads to additional enriching of products in saturated HCs. 
TABLE 4

Compositions of mazout and products obtained by MT of its mixtures with brown coal

\begin{tabular}{|c|c|c|c|c|c|c|}
\hline \multirow{2}{*}{$\begin{array}{c}\text { Sample, coal/mazout } \\
\text { proportion }\end{array}$} & \multicolumn{6}{|c|}{ Content, wt. $\%$, of } \\
\hline & saturated HCs & mono-arenes & biarenes & polyarenes & resins & Asphaltenes \\
\hline Initial mazout & 46.9 & 7.1 & 3.9 & 15.0 & 10.8 & 2.5 \\
\hline $10: 90$ & 65.6 & 3.1 & 4.0 & 12.6 & 10.6 & 1.4 \\
\hline $20: 80$ & 57.7 & 6.7 & 1.7 & 20.2 & 9.7 & 0.9 \\
\hline $30: 70$ & 55.8 & 3.4 & 3.6 & 15.2 & 11.2 & 0.9 \\
\hline $40: 60$ & 49.2 & 10.9 & 3.3 & 15.7 & 6.9 & 1.4 \\
\hline $50: 50$ & 52.3 & 12.0 & 5.2 & 13.9 & 9.3 & 1.5 \\
\hline $60: 40$ & 67.3 & 1.2 & 3.6 & 14.0 & 6.2 & 2.4 \\
\hline $70: 30$ & 68.0 & 1.1 & 1.7 & 14.2 & 9.7 & 1.4 \\
\hline
\end{tabular}

It is likely that in the process of mechanoactivation of the mixture of solid (coal) and liquid (mazout) phases the chemical transformations occur in initial compounds of both phases (molecular decomposition) as with arising radicals (reactions of aromatization, addition, cyclization and others). Equiprobable behavior of both processes is responsible for the complicated dependence of MA products' composition on the quantity of solid phase in the mixture.

This demonstrates that saturated products of coal destruction bring an essential contribution to the composition of the total products obtained. Alkylbenzene fragments, obviously, also play a noticeable role in molecular structures of coal components. Indicative of this are increased contents of monoarenes in products obtained from coal/mazout mixtures of 40:60 and 50:50 compositions up to 11-12 wt.\% instead of only about $7 \%$ in the initial mazout. However, the MT products produced from mixtures consisting of more than $50 \%$ of coal particles were very poor in monoarenes (only 1.1-1.2 wt.\%) for some unclear reasons.

Naphtalene nuclei are presented in small amounts both in mazout and coal molecules, as portions of biarenes in the initial liquid, and in most products produced from the treated mixtures did not exceed $4 \mathrm{wt} . \%$.

Tri- and polyarenic compounds are most widely distributed among aromatic hydrocarbon components of the intial mazout and all MT products of the mixtures under consideration (13-15 wt.\% of polyarenes in most cases), taking second place among all components of these substances. This points to the great significance of such condensed nuclei in both mazout and, especially, coal molecules.

Resins are the main high-molecular heteroatomic components of all the considered products (6-11 wt.\%), asphaltenes being only minor ones (1-2.5\%, Tab. 4).

We believe that the results presented are of interest at least in the two following aspects: they demonstrate clearly the possibilities of using mechanical activation for processing of heavy petroleum components and solid combustible fossils, and give new information about the compositional and structural features of these valuable natural products.

\section{CONCLUSIONS}

Mechanical treatment of heavy crude oils and petroleum residua leads to destruction of the high-molecular $n$-alkanes present, first of all, i.e. to partial deparaffinization of the product, and to formation of new amounts of low-boiling gasoline and diesel petroleum fractions. Mechanoactivation destruction of petroleum heavy components occurs most effectively when about $5 \mathrm{wt} . \%$ of powdered quartz particles are added to the liquid raw material and results in an almost two-fold decrease in paraffin content in crude oil.

The efficiency of mechanical destruction of resin and asphaltene components of petroleum residues (mazouts $>350^{\circ} \mathrm{C}$ ) may be heightened significantly by means of preliminary ozonization of stock and addition of a proton-donor component (tetraline, for example) into the mechanical treating system.

Mechanical treatment of mazout/coal mixtures, the first serving as solvent and proton-donor substance simultaneously, may be used as a new effective method to involve fossil solid fuels in processing and to produce additional amounts of more valuable liquid hydrocarbons.

\section{REFERENCES}

1 Dneprovsky K.S., Golovko A.K., Lomovsky O.I., Vosmerikov A.V. (1999) The study of mechanochemical treatment effect on the composition of gasoline oil fraction. 39th Int. Petroleum Conf., Bratislava, Slovak Republic, September 20-23.

2 Dubinskaya A.M. (1999) Prevrasheniya organicheskikh veshestv pod deistviem mechanicheskikh napryajenii, Uspekhi khimii (rus) J. 68, 8, 708-724, Moscow.

3 Orfanova M.N., Mistkan V.N. (1993) Mechanoactivation of Natural Gas. 1st Int. Conf. on Mechanochemistry, Kosice, Slovakia, March 23-26.

4 Molchanov V.I. (1988) Aktivatsiya mineralov pri izmelichenii (rus), Nedra, Moscow.

5 Gerhard H.B. (1984) Tribochemistry of quartz, Tribochemistry, Aredemie-Verlag, Berlin.

6 Baramboim N.K. (1978) Mechanochimiya visokomolekulyrnikh soedinenii (rus), Chimiya, Moscow. 
7 Goldberg E.L., Pavlov S.V. (1993) A model of Mechanical Activation. 1st Int. Conf. on Mechanochemistry, Kosice, Slovakia, March 23-26.

8 Polubentsev A.V., Proidakov A.G., Kuznetsova L.A., Kanitskaya L.V. (1991) Liquefaction of mechanically activated coals, Siberian Chem. J. 5, 105-114, Novosibirsk.

9 Davaatseren B., Golovko A.K., Tuyaa M. (2006) A study into Mechanochemical Conversion of the High Paraffin Tamsagbulag Oil (Mongolia). 6th Int. Conf. on Oil and Gas Chemistry, Tomsk, Russia.

10 Mamylov G.G., Gamolin O.E., Efremova N.V., Lomovsky O.I., Golovko A.K. (2003) Mechanochemically activated transformations in hydrocarbons. 4th Int. Conf. on Oil and Gas Chemistry, Braunshweig, Germany, September 7-11.

11 ISO 3405-88, Methods for determination characteristics.

12 ISO 3104-94, Determination of kinematic viscosity.
13 Bogomolova A.I., Temyanko M.B., Khotintseva L.I. (1984) Sovremennie metodi analiza neftei (rus), Nedra, Leningrad, Russia.

14 Patrakov Yu.F. (1988) Vibor metodiki dlya izucheniya kinetiki ojijeniya barzasskogo sapromeksita v nizkotermicheskikh usloviyakh. Chimiya tverdogo topliva (rus), Moscow, Russia, 3, 134-137.

15 Davaatseren B, Golovko A.K, Tuyaa M. (2006) A Study of the Ozonolysis Effect on the Properties of Tamsagbulag Oil (Mongolia), 6th Int. Conf. Oil and Gas Chemistry, Tomsk.

16 Batsanov S.S. (1987) O vozmojnosti protekaniya chimicheskikh reakcii v zone visokikh dinamicheskikh davlenii. Chimichaskaya phyzika (rus), Moscow, 6, 11, 1576-1582.

Final manuscript received in September 2007

Copyright (c) 2007 Institut français du pétrole

Permission to make digital or hard copies of part or all of this work for personal or classroom use is granted without fee provided that copies are not made or distributed for profit or commercial advantage and that copies bear this notice and the full citation on the first page. Copyrights for components of this work owned by others than IFP must be honored. Abstracting with credit is permitted. To copy otherwise, to republish, to post on servers, or to redistribute to lists, requires prior specific permission and/or a fee: Request permission from Documentation, Institut français du pétrole, fax. +33147527078 , or revueogst@ifp.fr. 